\title{
Laboreal
}

Volume $4 \mathrm{~N}^{\circ} 2$ | 2008

A inovação

\section{Experiência e redefinição da tarefa no trabalho das enfermeiras do horário nocturno: uma investigação em unidades de pneumologia}

Experiencia y redefinición de la tarea en el trabajo de las enfermeras de noche: una investigación realizada en unidades de neumología

Expérience et redéfinition de la tâche dans le travail des infirmières de nuit: une recherche menée dans des unités de pneumologie

Experience and task redefinition in the work of night call nurses: a research in pneumology units

\section{Cathy Toupin}

\section{OpenEdition}

Journals

\section{Edição electrónica}

URL: http://journals.openedition.org/laboreal/11458

DOI: 10.4000/laboreal. 11458

ISSN: 1646-5237

\section{Editora}

Universidade do Porto

Refêrencia eletrónica

Cathy Toupin, « Experiência e redefinição da tarefa no trabalho das enfermeiras do horário nocturno: uma investigação em unidades de pneumologia », Laboreal [Online], Volume 4 N² | 2008, posto online no dia 01 dezembro 2008, consultado o 24 setembro 2020. URL : http://journals.openedition.org/ laboreal/11458; DOI : https://doi.org/10.4000/laboreal.11458

Este documento foi criado de forma automática no dia 24 setembro 2020.

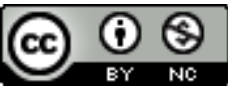

Laboreal está licenciado com uma Licença Creative Commons - Atribuição-NãoComercial 4.0 Internacional. 


\section{Experiência e redefinição da tarefa no trabalho das enfermeiras do horário nocturno: uma investigação em unidades de pneumologia}

Experiencia y redefinición de la tarea en el trabajo de las enfermeras de noche: una investigación realizada en unidades de neumología

Expérience et redéfinition de la tâche dans le travail des infirmières de nuit: une recherche menée dans des unités de pneumologie

Experience and task redefinition in the work of night call nurses: a research in pneumology units

Cathy Toupin

\section{REFERÊNCIA}

Toupin, C. (2008). Expérience et redéfinition de la tâche dans le travail des infirmières de nuit: Une recherche menée dans des unités de pneumologie. Thèse de doctorat, CNAM, Paris.

\section{NOTA DO EDITOR}

Manuscrito recebido em: Setembro/2008

Aceite após peritagem em: Novembro/2008 


\section{Os desafios de um estudo sobre a experiência do trabalho nocturno no sector hospitalar}

1 Entre as características do trabalho susceptíveis de influenciar os processos de regulação relacionados com a experiência, as questões do horário são pouco - quase nada - abordadas (apesar de serem abundantemente estudadas pela ergonomia; cf. Barthe, Quéinnec, \& Verdier, 2004; Gadbois, 2002, 2004). O objectivo desta tese é de colocar em evidência, numa população de enfermeiras hospitalares a trabalhar em horário nocturno, as competências específicas elaboradas no decorrer do percurso profissional que permitem fazer face às especificidades e constrangimentos inerentes a este período do ciclo circadiano; e de propor um modelo dinâmico de articulação entre horários e actividade de trabalho, estando atento ao modo como esta articulação se elabora ao longo da vida de trabalho com a experiência.

2 Esta questão de investigação apresenta um desafio social forte no meio hospitalar. A actividade do pessoal que presta cuidados de saúde durante a noite é singular e penosa (Mardon \& Toupin, 2007). Ora, neste sector, colocam-se questões sobre a profissão "prestador de cuidados de saúde nocturno", nomeadamente no que diz respeito à sua formação específica, e - num contexto em que se misturam sentimentos de mal-estar e falta de reconhecimento - da difícil construção da sua identidade sócio-profissional.

3 Estas dificuldades inserem-se, para além disso, num contexto sócio-demográfico particular, com: por um lado um envelhecimento da população activa hospitalar que vai conduzir determinados prestadores de cuidados a praticar o trabalho nocturno até uma idade bastante avançada e, por outro lado, uma chegada massiva de mais jovens na profissão; o que vai fazer coexistir, de noite, duas gerações de prestadores de cuidados, de idades e experiências diversas.

4 Este contexto sócio-demográfico, associado às condições de trabalho específicas dos estabelecimentos hospitalares, implica a interrogação, nomeadamente através das noções de construção e de transmissão de competências, sobre a elaboração e as manifestações de uma experiência específica das enfermeiras dos horários nocturnos.

\section{De um questionamento sobre a «experiência à noite» $a$ uma abordagem fundada na «redefinição da tarefa»}

5 Várias razões teóricas sustentam e justificam a ideia de atribuir um espaço importante para a análise das «tarefas» no processo de elucidação da experiência das prestadoras de cuidados no horário da noite.

6 A compreensão da experiência dos operadores passa nomeadamente por dar a ver as suas competências e o seu desenvolvimento com a antiguidade. Ora, uma forma de esclarecer esta noção de competência é a de a articular com as de tarefa e de actividade (Leplat, 1991), e, então, ao sentido que assume esta última para o operador, aos objectivos efectivamente visados por este (Savoyant, 1999).

7 Utilizámos a noção de «tarefa redefinida», proposta em ergonomia por Leplat (1997), que ele definiu como operacionalização da tarefa prescrita - um objectivo dado em condições determinadas -, em função de condições existentes que têm forçosamente características diferentes das prescritas formalmente pela organização. A tarefa 
redefinida tem em conta diferentes objectivos, mais ou menos conflituais, que deve preencher a tarefa prescrita (relativos à produção, à saúde, à actividade colectiva, etc.). O agente colocado em situação de conflito deverá encontrar um compromisso entre estes objectivos. Clarificamos que a actividade de um operador é constituída, não somente da própria execução da tarefa, mas igualmente das representações e redefinições que a acompanham e a guiam.

No nosso estudo, procurou-se colocar em evidência tais processos de redefinição, e de mostrar de que forma estes últimos são construtores, constitutivos e reveladores de experiência.

Colocar a hipótese de uma experiência específica do trabalho nocturno implica, igualmente, interessar-se pelas tarefas «temporalmente situadas» (Mayen, 2008).

Para falar da experiência das enfermeiras em horário nocturno era necessário compreender a sua tarefa, muito específica neste período. Nos serviços de saúde estudados, o trabalho efectuado pelas prestadoras de cuidados não é radicalmente diferente entre a noite e o dia, mas apresenta particularidades no período nocturno. Colocamos a hipótese de que as enfermeiras do horário nocturno redefinem a sua tarefa, em função de certas particularidades da sua actividade neste período: o estado particular dos pacientes (angústia, fadiga, solidão, etc.); as características da sua equipa de trabalho (número reduzido de efectivos, ausência de médicos) e o seu próprio estado psicofisiológico (fadiga, baixa de vigilância). Na nossa opinião, a experiência «no» trabalho à noite alimentar-se-ia de uma experiência destas especificidades, desafios e constrangimentos da tarefa nocturna.

\section{Métodos de análise}

11 O nosso estudo desenvolveu-se junto de enfermeiros do turno nocturno fixo de dois serviços de pneumologia de centros hospitalares franceses, que acolhem pacientes que apresentam patologias pulmonares diversas e/ou hospitalizados para diagnóstico e tratamento de cancro bronco-pulmonar.

Depois de uma primeira fase de familiarização nos serviços de cuidados, conduzimos uma análise aprofundada da actividade de 6 enfermeiras do horário nocturno (com idades compreendidas entre 26 e os 55 anos e uma experiência no trabalho nocturno de 2 meses a 34 anos), seguindo, cada uma delas, várias noites durante todo o período de duração do seu turno (21h-7h). No momento das observações, registamos: o conjunto de acções e trocas efectuadas pelas enfermeiras ao longo da noite, dados sobre a fadiga física da prestadora de cuidados e diversas informações sobre os pacientes que estavam sob a sua responsabilidade (patologias, prescrições, níveis de fadiga/ angústia/ dor/ etc.). Posteriormente, restituímos a cada enfermeira, através de uma entrevista de autoconfrontação individual, uma parte das nossas observações sobre o seu próprio trabalho, pedindo-lhes para comentar. As enfermeiras deveriam comentar as situações para as quais nos pareceu ter identificado objectivos de acção específicos ao período, tensões possíveis entre estes últimos e, então, as escolhas/arbitragens com que tinham que lidar.

13 Todavia, falar das especificidades da actividade de prestação de cuidados de saúde à noite necessita, num esforço de consolidação das nossas hipóteses, de ter alguns elementos de caracterização da tarefa e da actividade das prestadoras de cuidados 
durante o dia. Neste sentido, realizámos algumas observações em período diurno, e conduzimos entrevistas de allo-confrontação junto de três enfermeiras do horário diurno (sendo que uma já tinha sido enfermeira no horário nocturno). Tratava-se de apresentar a estas enfermeiras as situações observadas durante a actividade de uma das suas colegas que trabalha no horário nocturno, bem como excertos das entrevistas de auto-confrontação associadas a cada uma destas situações. O nosso objectivo era colocar em evidência as particularidades de cada situação de acordo com os momentos do dia ou da noite.

\section{O trabalho das enfermeiras no horário nocturno: objectivos diversos e, por vezes, divergentes}

As condições de realização da tarefa prescrita das enfermeiras no turno nocturno são específicas, tendo em conta as particularidades da vida no hospital neste período do ciclo circadiano, e do seu próprio estado psicofisiológico. Neste contexto particular, as prestadoras de cuidados constroem um significado nocturno da sua tarefa prescrita, redefinindoa, prescrevendo-se objectivos de acção «temporalmente situados», e acções a realizar para os cumprir. Estes objectivos procuram:

- assegurar a conformidade dos cuidados, acomodando-se o melhor possível à ausência dos médicos;

- consolidar os seus conhecimentos sobre o estado dos pacientes, adormecidos e isolados nos seus quartos uma larga parte da noite (visitando-os espontaneamente alguns no decurso da noite, deixando as portas de determinados quartos abertas, etc.);

- preservar o repouso dos pacientes, cansados pela doença e pelas solicitações diurnas (fechando a porta dos quartos, avançando/reportando/anulando determinadas prescrições, etc.);

- apaziguar as angústias nocturnas dos pacientes (permitindo aos mais angustiados de verificarem que são vigiados toda a noite - passando pelos quartos, não fazendo escuro e silêncio completo no serviço - etc.);

- preservar-se fisicamente ao longo da noite, e preservar os outros membros da equipa (organizando a actividade de forma a prevenir a acumulação de cansaço e a baixa de vigilância, atribuindo-se períodos de descanso, etc.);

- favorecer a aquisição e partilha de conhecimentos relativos à actividade de prestação de cuidados, nomeadamente nocturnos (favorecendo momentos de trocas e de aprendizagens). Estes objectivos podem, em determinadas situações, revelarem-se contraditórios, em termos de acções a levar a cabo para lhes dar resposta. Por exemplo: deve-se, ou não, administrar um nebulizador prescrito a um paciente adormecido sob pena de ele o acordar? Deve-se assegurar uma função de vigilância toda a noite (passando pelos quartos, deixando as portas abertas), ou privilegiar o respeito pelo sono dos pacientes?

\section{0 papel da experiência na redefinição nocturna da tarefa e a gestão da tensão entre os objectivos}

15 Identificar e responder às exigências de cada um dos objectivos de acção e gerir as contradições resultantes necessita de competências particulares e é revelador e construtor de experiência. 
16 Nas primeiras noites passadas num serviço de cuidados, as especificidades dos objectivos não surgem sempre claramente aos enfermeiros. Tomemos o seguinte exemplo: «Eu, no início, tinha nebulizações prescritas às $22 \mathrm{~h},(. .$.$) mesmo se eles$ estivessem a dormir, era preciso ministrá-las. Era assim e não de outra forma.» Esta enfermeira aplicava estritamente as prescrições médicas e não tinha consciência da necessidade de procurar preservar o sono do seu paciente.

No final de algumas semanas/meses, as enfermeiras percebem mais claramente as especificidades e importância nocturna dos objectivos guiarem a sua actividade, e distinguem as tensões que podem existir entre estes. Confrontadas com tais situações elas realizam arbitragens e compromissos (segundo critérios diversos: a hora de ocorrência do acontecimento, o estado do paciente, o conhecimento que detêm dos pacientes, etc.), cuja realização depende fortemente da sua experiência/antiguidade no trabalho nocturno.

18 Diversos registos de experiências determinam estes processos [nós inspiramo-nos na categorização proposta por Chassaing (2006), na sua tese sobre a elaboração gestual com a experiência]:

- a experiência resultante da prática profissional (confrontação com situações problemáticas, atitudes dos pacientes, conhecimentos relativos à prática do dia / outras profissões de prestação de cuidados, etc.);

- a experiência resultante da prática dos colegas de trabalho (observação dos modos operatórios, conselhos e relato de eventos);

- e o conhecimento de si e das suas capacidades psicofisiológicas (evolução dos níveis de fadiga e de vigilância ao longo da noite e ao longo de noites de trabalho sucessivas).

\section{Perspectivas de acção e de investigação}

19 Em termos de aplicação, esta investigação propõe marcos de referência para melhorar a situação de trabalho e o reconhecimento das enfermeiras do horário nocturno. As pistas de acção não procuram só um rearranjo das condições de trabalho. Dizem respeito a todos os meios (margens de manobra, ferramentas, formações, etc.) que possam favorecer, por um lado, a identificação, pelo pessoal hospitalar do horário nocturno, dos objectivos e tensões que caracterizam a sua situação de trabalho, por outro lado, a implementação destas arbitragens e compromissos que permitem lhes fazer face, em diversos momentos na sua noite de trabalho.

Algumas questões aparecerem no final do nosso estudo, abrindo a possibilidade para novas perspectivas de investigação; não faremos aqui mais do que evocar apenas algumas: a generalização dos nossos resultados a outro tipo de unidades de cuidado? 0 impacto da idade e das condições de vida fora do trabalho nos processos colocados em evidência no nosso estudo? Os riscos e custos físicos e psíquicos das arbitragens realizadas pelas enfermeiras? 


\section{BIBLIOGRAFIA}

Barthe, B., Quéinnec, Y., \& Verdier, F. (2004). L'analyse de l'activité de travail en postes de nuit: bilan de 25 ans de recherches et perspectives. Le travail Humain, 67, 1, 41-62.

Chassaing, K. (2006). Elaboration, structuration et réalisation des gestuelles de travail: les gestes dans l'assemblage automobile, et dans le coffrage des ponts d'autoroute. Thèse de Doctorat en Ergonomie, Conservatoire National des Arts et Métiers, Paris.

Gadbois, C. (2002). Pratique des horaires atypiques, âge et santé: une diversité de cas de figure, produits d'interactions jouant différemment selon les secteurs. Etude réalisée par le laboratoire d'Ergonomie Physiologique et Cognitive / EPHE, à la demande du Créapt/CEE. Paris.

Gadbois, C. (2004). Les discordances psychosociales des horaires postés: questions en suspens. Le Travail Humain. 67,(1), 63-85.

Leplat, J. (1991). Compétence et ergonomie. In R. Amalberti, M. de Montmollin \& J. Theureau (Eds.), Modèles en analyse du travail (pp. 263-278). Liège: Mardaga.

Leplat, J. (1997). Regards sur l'activité en situation de travail. Contribution à la psychologie ergonomique. Paris: PUF.

Mardon, C., \& Toupin, C. (2007). Psychosocial and physical risk factors depending on age and shifts among french nurses. Ergonomia. 29,(3-4), 105-110.

Mayen, P. (2008). L'expérience dans les activités de Validation des Acquis de l'Expérience. Travail et Apprentissage, 1, 58-75.

Savoyant, A. (1999). Compétence, performance et activité. In Entreprises et compétences: le sens des évolutions (pp. 179-191). Paris: ECRIN.

\section{AUTOR}

\section{CATHY TOUPIN}

Centre d'Etudes de l'Emploi (CEE), Centre de Recherches et d'Etudes sur l'Age et les Populations au Travail (CRÉAPT) 29, Promenade Michel Simon, 93166 Noisy-Le-Grand, France cathytoupin@yahoo.fr 